\title{
Measurement of intestinal permeability using mannitol and lactulose in children with diarrheal diseases
}

\author{
M.S. Barboza Jr. ${ }^{1}$, \\ T.M.J. Silva ${ }^{1,3}$, \\ R.L. Guerrant ${ }^{2}$ and \\ A.A.M. Lima ${ }^{1}$
}

\section{Correspondence \\ A.A.M. Lima \\ Unidade de Pesquisas Clínicas \\ Faculdade de Medicina, UFC \\ 60436-160 Fortaleza, CE \\ Brasil \\ Fax: + 55-85-281-5212 \\ E-mail: alima@ sec.secrel.com.br \\ Research supported by the National Institutes of Health (ICIDR No. PO 10-Al-26512 and TMRC No. 2P50AI30639-06). M.S. Barboza Jr. is the recipient of a PIBIC-CNPq fellowship.}

Received November 25, 1997 Accepted August 4, 1999

\begin{abstract}
${ }^{1}$ Departamento de Fisiologia e Farmacologia, U nidade de Pesquisas Clínicas, Faculdade de Medicina, Universidade Federal do Ceará, Fortaleza, CE, Brasil 2Division of Geographic and International Medicine and Infectious Diseases, University of Virginia, Health Sciences Center, Charlottesville, VA, USA ${ }^{3}$ Hospital São José de Doenças Infecciosas, Secretaria de Saúde do Estado, Fortaleza, CE, Brasil
\end{abstract}

\section{Abstract}

The excretion ratio of lactulose/mannitol in urine has been used to assess the extension of malabsorption and impairment of intestinal permeability. The recovery of lactulose and mannitol in urine was employed to evaluate intestinal permeability in children with and without diarrhea. Lactulose and mannitol probes were measured using high-performance liquid chromatography with pulsed amperometric detection (HPLC-PAD). Two groups of solutions containing $60 \mu \mathrm{M}$ sugars were prepared. Group I consisted of glucosamine, mannitol, melibiose and lactulose, and group II of inositol, sorbitol, glucose and lactose. In the study of intra-experiment variation, a sample of $50 \mu \mathrm{l}$ from each group was submitted to 4 successive determinations. The recovered amounts and retention times of each sugar showed a variation $<2$ and $1 \%$, respectively. The estimated recovery was $>97 \%$. In the study of inter-experiment variation, we prepared 4 independent samples from groups I and II at the following concentrations: 1.0, 0.3, $0.1,0.03$ and $0.01 \mathrm{mM}$. The amounts of the sugars recovered varied by $<10 \%$, whereas the retention times showed an average variation $<1 \%$. The linear correlation coefficients were $>99 \%$. Retention (k'), selectivity $(\alpha)$ and efficiency $(\mathrm{N})$ were used to assess the chromatographic conditions. All three parameters were in the normal range. Children with diarrhea presented a greater lactulose/mannitol ratio compared to children without diarrhea.

\section{Introduction}

The measurement of the urinary excretion of non-metabolized sugars administered orally is a useful molecular marker for noninvasive evaluation of the intestinal absorption area, transcellular and paracellular permeability as well as the integrity of the gastrointestinal mucosa (1). There are several diseases that are associated with modifica-

\section{Key words} - Permeability test

- Mannitol

- Lactulose

- HPLC-PAD

- Diarrhea tions in intestinal permeability manifesting clinically as diarrhea and weight loss: celiac disease (2), AIDS (3), Crohn's disease (4), protein-wasting enteropathy associated with Clostridium difficile (5), chronic diarrhea and malnutrition (6), and infectious diarrhea (7).

The use of non-metabolized sugars represents a marked improvement in determining changes in permeability and in obtaining knowledge about intestinal absorptive physiology 
itself. It is clear that the measurement of intestinal permeability based on the quantified absorption of two sugars of different sizes provides more information and shows higher sensitivity in gastrointestinal disorders than trials which use single sugars for the tests $(2,7)$. Mannitol and lactulose are preferred sugars because of their properties and their hydrophilic and lipophobic characteristics. They present small affinity for the glycoside transport system in the intestinal mucosa, therefore being passively absorbed and having the advantage of not being metabolized (8). Mannitol theoretically enters the cell through the hydrophilic portion of the cell membrane, whereas lactulose goes through the tight junctions and extrusion zones of the intervillous spaces. Consequently, the loss of mucosal integrity should cause increased lactulose absorption, while the loss of absorptive areas decreases the absorption of mannitol (9).

The determination of mono- and polysaccharides has been improved in the past years with the advent of the methodology of highperformance liquid chromatography with pulsed amperometric detection (HPLC-PAD) (1). This methodology permits the direct analysis of several molecules of sugars with high sensitivity and extremely simple sample preparation, basically avoiding interference by other substances present in the urine. Some versions of this methodology have been employed successfully to assess the lactulose/mannitol ratio in several clinical trials $(9,10)$.

In the present study, we determine the intestinal permeability using lactulose and mannitol in children with diarrheal diseases.

\section{Material and Methods}

\section{Sugars and chemicals}

Myo-inositol, D-(+)-glucosamine hydrochloride, sorbitol, mannitol, D-(+)-glucose, melibiose, $B$-lactose and lactulose were purchased from Sigma Chemical Co. (St. Louis, MO, USA) as standards for the analysis.
Low-carbonate $50 \%(\mathrm{v} / \mathrm{v})$ sodium hydroxide was used as eluent for HPLC.

\section{Apparatus}

The BioLC carbohydrate analyzer HPLC system, which was composed of a Module GPM-2 gradient pump, a Module EDM-II eluent degassing device and a PAD-II pulsed amperometric detector with a gold working electrode, was from Dionex (Sunnyvale, CA, USA). A CarboPac MA-1 anion-exchange column (250 x $4.0 \mathrm{~mm}$ i.d., pellicular resin) with an associated guard column was also from Dionex. The injections were performed manually.

\section{Sample preparation}

Two standard solutions of sugars were used to calibrate the HPLC-PAD system. Each standard contained $60 \mu \mathrm{M}$ of the following sugars: glucosamine, mannitol, melibiose and lactulose (group I), and inositol, sorbitol, glucose and lactose (group II). Standard solutions were used to calibrate the HPLC system at the beginning of the measurements and then after every four injections (four samples) to correct for the loss of sensitivity due to the accumulation of materials on the electrodes. For the determination of intra-experiment variation we employed groups I and II at the concentration of $0.1 \mathrm{mM}$. We took four $50-\mu \mathrm{l}$ samples from each group, which were analyzed successively. To determine the inter-experiment variation we prepared four independent samples from groups I and II at the concentration of $1.0 \mathrm{mM}$. The sugars were diluted from these solutions to the following concentrations: $1.0,0.3,0.1,0.03$ and $0.01 \mathrm{mM}$, and 50 $\mu \mathrm{l}$ of each sugar solution was analyzed. For the patient study we mixed $50 \mu$ of urine plus $50 \mu \mathrm{l}$ of a solution containing melibiose (3.6 mM) diluted in $2.9 \mathrm{ml}$ of twice-distilled and deionized water. After centrifugation, $50 \mu \mathrm{l}$ was employed for sugar determination by HPLC-PAD. 
Permeability test with lactulose and mannitol in children

In order to validate the intestinal permeability test using lactulose and mannitol, we studied a cohort of children from an ongoing project in diarrheal diseases followed by our group at the Clinical Research Unit, HUWC, Federal University of Ceará. This project was approved by the Human Investigation Committee at the same institution. The children were from a poor urban community of Gonçalves Dias, Fortaleza, CE, with a population of approximately 2000, located five blocks from our research laboratories. After the consent form for participation in the study was signed by their guardians, we assigned the children to two groups: diarrhea group $(\mathrm{N}=$ 15), defined as children with 3 or more liquid stools in the last $24 \mathrm{~h}$, and controls $(\mathrm{N}=15)$, consisting of children with no episode of diarrhea in the last 2 weeks. The two groups were matched for age (within \pm 3 months). The children did not differ significantly in nutritional status before the diarrhea episodes as measured by weight-for-age, height-for-age and weight-for-height z-scores. Children aged $<5$ years of both genders, controls and with diarrhea, were utilized to validate the permeability test with lactulose and mannitol. After a 3-h fast, children ingested a solution $(2 \mathrm{ml} / \mathrm{kg})$ containing mannitol $(50 \mathrm{mg} / \mathrm{ml})$ and lactulose $(200 \mathrm{mg} / \mathrm{ml})$. Urine was collected for $5 \mathrm{~h}$ into a flask containing $1 \mathrm{ml}$ of chlorhexidine $(40 \mathrm{mg} / \mathrm{ml})$ purchased from Sigma. The total urine volume was recorded and a sample of $10 \mathrm{ml}$ was stored at $-20^{\circ} \mathrm{C}$ for sugar determination by HPLC-PAD.

\section{Chromatographic conditions for HPLC analysis}

HPLC-PAD analysis for mono- and disaccharides was carried out using the Dionex BioLC apparatus described above. The sugars were eluted with an isocratic eluent of $480 \mathrm{mM} \mathrm{NaOH}$ at a flow-rate of $0.4 \mathrm{ml} / \mathrm{min}$, with the column kept at room temperature. Sugars were determined with a pulsed amperometric detector with the waveform consisting of the following potential-duration profile: sampling, $0.15 \mathrm{~V}, 720 \mathrm{~ms}$; oxidation, $0.70 \mathrm{~V}, 120 \mathrm{~ms}$; reduction, $-0.30 \mathrm{~V}, 360$ $\mathrm{ms}$. The output range of the detector was set at $1.0 \mathrm{~mA}$ with an integration response time of $3 \mathrm{~s}$. A 50- $\mu \mathrm{l}$ volume of each sample was injected manually and the analyses were quantitated using a BioAutoIon 450 Data System (Dionex).

\section{Data analysis}

The results are reported as means $\pm \mathrm{SD}$ and regression analyses were employed to determine the correlation coefficients of the standard sugars. The data were analyzed for intra- and inter-experiment precision, dilution linearity of the concentrations of the standards, percentage of sample recovery and specificity of separation of the tested sugars, including mannitol and lactulose. The permeability test using mannitol and lactulose was validated by the Wilcoxon test applied to data for age-matched healthy children (controls) and children with diarrhea.

\section{Results}

\section{Separation of sugars and precision of the HPLC-PAD method}

The fact that mannitol and lactulose are a monosaccharide and disaccharide, respectively, explains the difficulty in developing methods of separation and measurements utilizing enzymes for degradation. In this method we employed a CarboPac-MA1 column with resin packed in a non-metallic column body adequate for the determination and analysis of weakly ionized sugars in high concentrations of sodium hydroxide. The recovery and retention times of a mixture of sugars injected 5 times are shown in Tables 1 and 2, respectively. For the deter- 
mination of intra-experiment variation, the standard deviation was less than $1.9 \%$ for the recovery of sugar samples and less than $1.2 \%$ for the retention times. For inter-experiment determinations the average variation was $9.8 \%$ and the variation in retention times was less than $2 \%$.

\section{Linear variation of dilutions and percentage of recovery of standard samples}

The linear variation was evaluated by the correlation coefficient obtained from regression analysis of 5 injections of each standard

Table 1 - Intra- and inter-experiment variation and recovery of standard sugars measured by HPLC and pulsed amperometric detection.

The data are reported as means \pm SD of recovered picomoles of each sugar.

\begin{tabular}{|c|c|c|c|c|c|c|}
\hline \multirow[t]{2}{*}{ Sugar } & \multicolumn{3}{|c|}{ Intra-experiment } & \multicolumn{3}{|c|}{ Inter-experiment } \\
\hline & Mean \pm SD & $\begin{array}{c}\text { Variation } \\
(\%)\end{array}$ & $\begin{array}{c}\text { Recovery } \\
(\%)\end{array}$ & Mean \pm SD & $\begin{array}{c}\text { Variation } \\
(\%)\end{array}$ & $\begin{array}{c}\text { Recovery } \\
(\%)\end{array}$ \\
\hline Inositol & $4544 \pm 49$ & 1.1 & 90.9 & $4976 \pm 246$ & 5.0 & 90.9 \\
\hline Glucosamine & $4911 \pm 79$ & 1.6 & 98.2 & $4488 \pm 679$ & 15.1 & 98.2 \\
\hline Sorbitol & $4843 \pm 74$ & 1.5 & 96.9 & $4953 \pm 195$ & 3.9 & 96.9 \\
\hline Mannitol & $5075 \pm 91$ & 1.8 & 101.5 & $4810 \pm 426$ & 8.8 & 101.5 \\
\hline Melibiose & $4922 \pm 78$ & 1.6 & 98.4 & $4859 \pm 484$ & 10.0 & 98.4 \\
\hline Glucose & $4888 \pm 62$ & 1.3 & 97.8 & $5460 \pm 1197$ & 21.9 & 97.8 \\
\hline Lactulose & $4870 \pm 69$ & 1.4 & 97.4 & $4771 \pm 234$ & 4.9 & 97.4 \\
\hline Lactose & $4846 \pm 27$ & 0.6 & 96.9 & $5050 \pm 443$ & 8.8 & 96.9 \\
\hline Mean & $4862 \pm 148$ & 1.4 & 97.3 & $4921 \pm 277$ & 9.8 & 97.25 \\
\hline
\end{tabular}

Table 2 - Intra- and inter-experiment variation of retention times of standard sugars measured by HPLC and pulsed amperometric detection.

Data are reported as means \pm SD of recovered picomoles of each sugar.

\begin{tabular}{lrrrrr}
\hline \multirow{2}{*}{ Sugar } & \multicolumn{2}{c}{ Intra-experiment } & & \multicolumn{2}{c}{ Inter-experiment } \\
\cline { 2 - 3 } \cline { 5 - 6 } & Mean \pm SD & Variation (\%) & & Mean \pm SD & Variation (\%) \\
\hline Inositol & $6.85 \pm 0.07$ & 1.0 & & $6.74 \pm 0.02$ & 0.3 \\
Glucosamine & $13.73 \pm 0.11$ & 0.8 & & $13.46 \pm 0.12$ & 0.9 \\
Sorbitol & $14.56 \pm 0.14$ & 1.0 & & $14.09 \pm 0.06$ & 0.5 \\
Mannitol & $17.29 \pm 0.16$ & 0.9 & & $17.06 \pm 0.04$ & 0.2 \\
Melibiose & $21.10 \pm 0.22$ & 1.1 & & $20.40 \pm 0.33$ & 1.6 \\
Glucose & $22.07 \pm 0.19$ & 0.9 & & $21.26 \pm 0.22$ & 1.0 \\
Lactulose & $25.42 \pm 0.26$ & 1.0 & & $24.49 \pm 0.45$ & 1.9 \\
Lactose & $28.12 \pm 0.28$ & 1.0 & & $26.70 \pm 0.31$ & 1.2 \\
& & & & &
\end{tabular}

sugar used at the following concentrations: $1.0,0.3,0.1,0.03$ and $0.01 \mathrm{mM}$. The results analyzed were the average of four determinations for each concentration utilized. The correlation coefficients were $\mathrm{r}^{2}=1.0$ for mannitol, $\mathrm{r}^{2}=0.994$ for glucosamine, $\mathrm{r}^{2}=$ 1.0 for lactulose, $\mathrm{r}^{2}=0.998$ for melibiose, $\mathrm{r}^{2}=0.996$ for inositol, $\mathrm{r}^{2}=0.999$ for sorbitol, $r^{2}=0.999$ for lactose, and $r^{2}=1.0$ for glucose. Intra-experiment variation in percent of recovery of the standard samples ranged from 91 to $102 \%$ (Table 1) and inter-experiment variation ranged from 90 to $101 \%$ (Table 2).

\section{Chromatographic conditions}

To assess the ideal chromatographic conditions we utilized three parameters: k' (retention), $\alpha$ (selectivity) and $\mathrm{N}$ (efficiency). The k' values for mannitol, melibiose and lactulose were $2.53,3.15$ and 3.99 , respectively (normal range: $1 \leq \mathrm{k}^{\prime} \leq 10$ ). Selectivity $(\alpha)$ was 1.24 for melibiose/mannitol, 1.27 for lactulose/melibiose and 1.58 for lactulose/mannitol (normal range: $\alpha>1$ ). The efficiency of the column, i.e., number of plates, was 4395, 3642 and 3165 for mannitol, melibiose and lactulose, respectively.

\section{Validation of the permeability test using mannitol and lactulose}

Figure 1 shows a typical chromatogram of a healthy child and one with diarrhea. The lactulose peak was significantly higher in the child with diarrhea compared to that for the healthy child.

\section{Evaluation of the intestinal permeability in children}

Analysis of the intestinal permeability of healthy children (controls) using the lactulose/mannitol test (Figure 2) showed a significant decrease in percent lactulose excretion in urine compared to children with diar- 
rhea $(0.3029 \pm 0.2846, \mathrm{~N}=15$ vs $0.1183 \pm$ $0.0855, \mathrm{~N}=15 ; \mathrm{P}<0.02)$. A significant reduction in the lactulose/mannitol ratio was also observed when controls were compared to children with diarrhea $(0.1404 \pm 0.1206$, $\mathrm{N}=15$ vs $0.0394 \pm 0.0235, \mathrm{~N}=15 ; \mathrm{P}=$ 0.001). Percent mannitol excretion did not differ significantly between groups (Figure 2).

\section{Discussion}

Reports on intestinal permeability measurements $(11,12)$ have considered the lactulose/mannitol ratio a primary parameter for the normal functioning of intestinal epithelial cells. We have previously evaluated this parameter in human immunodeficiency virus infection (1). The current study revalidates this parameter in children with and without diarrheal diseases, from a poor urban community, Gonçalves Dias, in Fortaleza, Brazil.

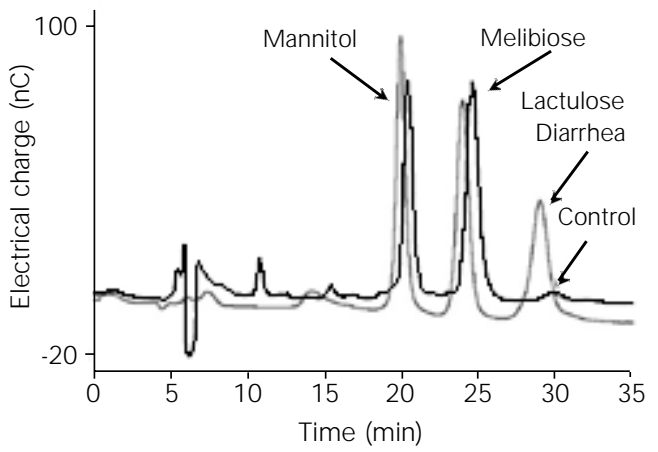

Figure 1 - Detection of lactulose and mannitol in urine of children with and without diarrhea. The figure shows two chromatograms of the lactulose and mannitol peaks for children with and without diarrheal disease. The mannitol peak showed no significant difference between children with diarrhea and healthy children. In contrast, children with diarrhea had a higher peak for lactulose compared to children without diarrhea, suggesting a change in intestinal permeability or mucosal damage. Melibiose peaks in both chromatograms are used as control internal standards for the quantification of the sugars.
The linearity of the method employed here was demonstrated by the addition of known quantities of standards (eight types of sugars analyzed) in a volume of $50 \mu \mathrm{l}$. A linear relationship was shown for concentrations ranging from 0.01 to $1.0 \mathrm{mM}$ of each standard, indicating the considerable reproducibility of the technique.

The chromatographic conditions as measured by retention, selectivity and efficiency were within the normal range, suggesting that the technique was appropriate for separation and detection of all standard sugars. The HPLC-PAD method to detect lactulose and mannitol was precise and sensitive.

Evaluation of intestinal permeability by the lactulose/mannitol test proved to be appropriate and sensitive when children with diarrhea were compared to healthy controls. There was a significant reduction in lactulose excretion in the urine as well as in the

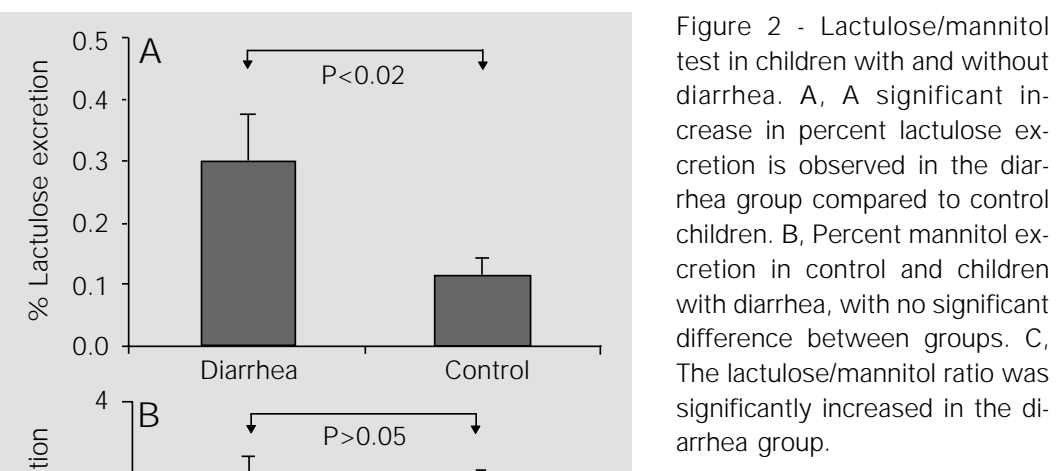
arrhea group. 
lactulose/mannitol ratio of the control group. On the other hand, mannitol excretion did not differ significantly between groups. The data suggest that the lactulose/mannitol test associated with HPLC-PAD detection of sugars might be a useful, easy and sensitive method of measuring intestinal permeability in children with or without diarrhea. Moreover, these data reinforce our previous results using the same technique for adult HIV+ patients with and without diarrheal diseases (1). The results further agree with and extend information published by others $(13,14)$ on intestinal permeability and epithelium damage observed in children with diarrhea and malnutrition. A recent report by Goto et al. (15) showed that the median urinary lactulose/mannitol recovery ratio in asymptomatic infants who had diarrhea during the week before testing was higher than that in children who had been free from diarrhea for at least one week. These results also suggested that recent diarrhea was associated with altered intestinal function in this group of Guatemalan infants (15).

In conclusion, the present results support the potential use of this method for the detection and quantification of several sugars, including lactulose and mannitol. These data also validate the use of lactulose and mannitol as molecular markers to assess changes in intestinal permeability in healthy children and children with diarrheal diseases. Furthermore, this permeability test has potential as a noninvasive method for monitoring the response to therapy in children with diarrheal diseases.

\section{References}

1. Bao Y, Silva TMJ , Guerrant RL, Lima AAM \& Fox J W (1996). Direct analysis of mannitol, lactulose and glucose in urine samples by high-performance anion-exchange chromatography with pulse amperometric detection: clinical evaluation of intestinal permeability in human immunodeficiency virus infection. J ournal of Chromatography. B, Biomedical Applications, 685: 105-112.

2. Pearson $A D$, Eastham J , Laker MF, Craft A \& Nelson R (1982). Intestinal permeability in children with Crohn's disease and celiac disease. British Medical J ournal, 285: 20-21.

3. Tanowitz HB, Simon D \& Wittner M (1992). Gastrointestinal manifestations. Medical Clinics of North America, 76: 4561.

4. Teahon K, Smethurst P, Levi AJ , Menzies IS \& Bjamason I (1992). Intestinal permeability in patients with Crohn's disease and their first degree relatives. Gut, 33: 320-323.

5. Rybolt $A H$, Laughon $B E$, Greenough III WB, Bennett RG, Thomas DR \& Bartlett J G (1989). Protein-losing enteropathy associated with Clostridium difficile infec- tion. Lancet, i: 1353-1355.

6. Lunn PG, Northrop-Clewes CA \& Downes RM (1991). Chronic diarrhea and malnutrition in the Gambia: Studies of intestinal permeability. Transactions of the Royal Society of Tropical Medicine and Hygiene, 85: 8-11.

7. Silva ES (1994). Estudo do conteúdo de lactoferrina fecal em diarréia infecciosa. Master's thesis, Universidade Federal do Ceará, Fortaleza, CE.

8. Laker MF \& Menzies IS (1977). Increase in human intestinal permeability following ingestion of hypertonic solutions. J ournal of Physiology, 265: 881-894.

9. Fleming SC, Kapembwa MS, Laker MF, Levin GE \& Griffin GE (1990). Rapid and simultaneous determination of lactulose and mannitol in urine, by HPLC with pulsed amperometric detection, for use in studies of intestinal permeability. Clinical Chemistry, 36: 797-799.

10. Simon D, Weis LM, Tanowitz HB, Cali A, J ones J \& Wittner M (1990). Light microscopic diagnosis of human microsporidiosis and variable response to octreotide. Gastroenterology, 100: 271-273.

11. Bijlsma PB, Peeters RA, Groot J Á, Dekker
PR, Taminiau J AJ M \& Meer RVD (1995). Differential in vivo and in vitro intestinal permeability to lactulose and mannitol in animals and humans: a hypothesis. Gastroenterology, 108: 687-696.

12. Travis $S \& \&$ Menzies I (1992). Intestinal permeability: functional assessment and significance. Clinical Science, 82: 471488.

13. Behrens R, Lunn PG, Northrop CA, Hanlon PW \& Neale G (1987). Factors affecting the integrity of the intestinal mucosa of Gambian children. American J ournal of Clinical Nutrition, 45: 1433-1441.

14. Ford RP, Menzies IS, Phillipis AD, WalkerSmith J A \& Tumer MW (1985). Intestinal sugar permeability: relationship to diarrheal disease and small bowel morphology. J oumal of Pediatric Gastroenterology and Nutrition, 4: 568-574.

15. Goto K, Chew F, Torun B, Peerson J M \& Brown KH (1999). Epidemiology of altered intestinal permeability to lactulose and mannitol in Guatemalan infants. J ournal of Pediatric Gastroenterology and Nutrition, 28: 282-290. 